\title{
HUMANIZAÇÃO E EDUCAÇÃO POPULAR EM SAÚDE PARA PESSOAS EM VULNERABILIDADE SOCIOECONÔMICA
}

\section{HUMANIZATION AND POPULAR HEALTH EDUCATION FOR PEOPLE IN SOCIOECONOMIC VULNERABILITY}

\author{
Vinícius Gonçalves de Souza* \\ ORCID: https://orcid.org/0000-0002-1656-6928 \\ Thalía Rissa Silva** \\ ORCID: https://orcid.org/0000-0001-6118-7786 \\ Jhordana Esteves dos Santos*** \\ ORCID: https://orcid.org/0000-0003-2276-4362 \\ Francisco Inácio de Assis Neto**** \\ ORCID: https://orcid.org/0000-0001-9046-4500 \\ Luís Henrique da Silva Lima***** \\ ORCID: https://orcid.org/0000-0001-9089-3129 \\ Michelle Rocha-Parise****** \\ ORCID: https://orcid.org/0000-0003-1150-3693
}

\section{Resumo}

Os Centros de Referência de Assistência Social destacam-se na assistência à população em situação de vulnerabilidade social. Considerando a importância da disseminação de informações sobre saúde a este público, este trabalho objetiva relatar a implantação e execução do projeto de extensão "Informação é Saúde", de modo a contribuir para os conhecimentos acerca da extensão Universitária no contexto da Educação Popular em Saúde em unidades socioassistenciais do município de JataíGoiás. As metodologias empregadas nos encontros incluíram: rodas de conversa, dinâmicas de perguntas e respostas, discussão sobre mitos e verdades, problematizações de situações clínicas, artes plásticas, artes cênicas e criação de material audiovisual. As atividades objetivaram ações de Educação Popular em Saúde para a garantia da integralidade e da equidade em saúde e da humanização do cuidado, sobretudo para o público em vulnerabilidade socioeconômica atendido neste projeto e os resultados positivos reforçam a importância de projetos com esse enfoque.

Palavras-chave: Promoção da saúde; Equidade; Disseminação de informação; Integralidade em saúde; Relações comunidade-instituição.

Data recebimento: $16 / 02 / 2021$

Data de aceite: $14 / 06 / 2021$

\begin{abstract}
The Social Assistance Referral Centers provide notorious assistance to the population in situations of social vulnerability. Considering the importance of the dissemination of information about health to this public, this work aims to report the implementation and execution of the extension project 'Information is Health' in order to contribute to the knowledge about university outreach in the context of Popular Education in Health in social assistance units in the municipality of Jataí-Goiás, The methodologies employed in the meetings included: conversation circles, question and answer dynamics, discussion of myths and truths, the problematization of clinical situations, visual arts, performing arts, and creation of audiovisual material. The activities reinforced the importance of actions of Popular Health Education to guarantee integrality and equity in health and humanization of care, especially for the public in socioeconomic vulnerability assisted in this project.
\end{abstract}

Keywords: Health promotion; Health equity; Information dissemination; Integrality in health; Community-institutional relations.

* Aluno de Graduação da Universidade Federal de Jataí (UFJ), Jataí - GO, Brasil. E-mail: viniciusgoncalves@discente.ufj.edu.br

** Aluna de Graduação da Universidade Federal de Jataí (UFJ), Jataí - GO, Brasil. E-mail: thaliarissa@uj.edu.br

*** Aluna da Universidade Federal de Jataí (UFJ), Jataí - GO, Brasil. E-mail: estevesjhordana@gmail.com

**** Aluno de Graduação da Universidade Federal de Jataí (UFJ), Jataí - GO, Brasil. E-mail: erabrasileira@gmail.com

***** Aluno de Graduação da Universidade Federal de Jataí (UFJ), Jataí - GO, Brasil. E-mail: luishlima@gmail.com

****** Professora da Universidade Federal de Jataí (UFJ), Jataí - GO, Brasil. Doutorado em Farmacologia. E-mail: microcha123@ufj.edu.br 


\section{Introdução}

A partir da Constituição Federal de 1988, a assistência social passou a ser tratada como política pública de direito e a desigualdade social recebeu destaque como fator associado à saúde. Com base na referida Constituição, em 1993 foi elaborada a Lei Orgânica de Assistência Social (LOAS), que segue o tripé da seguridade social e compreende saúde, previdência e assistência social (BRASIL, 1993)

\footnotetext{
Art. $1^{\circ}$ A assistência social, direito do cidadão e dever do Estado, é Política de Seguridade Social não contributiva, que provê os mínimos sociais, realizada através de um conjunto integrado de ações de iniciativa pública e da sociedade, para garantir o atendimento às necessidades básicas (BRASIL, 1993)
}

Ainda, a LOAS determina que os serviços de assistência social devem unir forças com demais campos de políticas públicas, como a assistência em saúde, para garantir o atendimento às necessidades básicas dos cidadãos.

Para assegurar o cumprimento de suas ações, foi criado, em 2004, o Sistema Único de Assistência Social (SUAS), que segue determinações da Política Nacional de Assistência Social (PNAS), segundo a qual o serviço de assistência deve se articular com outros setores, incluindo saúde, educação, cultura, esporte, empregos e habitação (MINISTÉRIO DO DESENVOLVIMENTO SOCIAL E COMBATE À FOME, 2004).

Dentre as unidades do SUAS, os Centros de Referência de Assistência Social (CRAS) destacam-se na assistência à população em situação de vulnerabilidade e risco pessoal e/ou social, em todo o território nacional. Essas unidades se inserem, fundamentalmente, no contexto da Proteção Social Básica, que objetiva a prevenção de situações de risco e o fortalecimento dos vínculos familiares e comunitários (BRASIL, 1993; MINISTÉRIO DO DESENVOLVIMENTO SOCIAL E COMBATE A FOME, 2004). Os problemas de saúde física e mental são parte importante da demanda de assistência oferecida pelos CRAS (TEIXEIRA, 2010). Esses centros corroboram os princípios da LOAS e da PNAS, pois desempenham função importante na promoção da saúde e do bem-estar, conforme a demanda da comunidade local.

Nesse contexto, a promoção da saúde é pautada por determinados conceitos, dentre eles o de Educação em Saúde, que se destaca como uma estratégia que viabiliza o aprendizado e o compartilhamento de informações. A Educação em Saúde foi idealizada para valorizar a relação entre profissional de saúde e paciente, auxiliar na horizontalidade do cuidado e na popularização do conhecimento, por ser o paciente um sujeito crítico, criativo, proativo e autônomo nas decisões em saúde (FIGUEIREDO; NETO; LEITE, 2010; SANTOS, 2006). Esse conceito foi ampliado posteriormente pelo modelo de Educação Popular em Saúde, que valoriza a autonomia e o protagonismo da população, além de aproximar o processo de cuidado do espaço comunitário e dos movimentos sociais (DO AMARAL; PONTES; SILVA, 2014).

Com base neste último modelo, instituiu-se a Política Nacional de Educação Popular em Saúde (PNEP-SUS) pela Portaria nº. 2.761, de 19 de novembro de 2013, que visa a valori- 
zação de saberes populares e a sua inserção no Sistema Único de Saúde (SUS) nas esferas da promoção, proteção e recuperação da saúde (BRASIL, 2013). Para o êxito dessa política, é importante que a relação entre indivíduo, família e profissional seja pautada na troca de experiências e na horizontalidade do conhecimento, respeitando os saberes populares e a sua relação com tecnologia e ciência (VASCONCELOS, 2001; VERDI; BUCHELE; TOGNOLI, 2010).

Nesse esteio, a literatura estabelece a escolaridade como um importante indicador de desenvolvimento socioeconômico, que influencia de forma direta o processo saúde-doença, destacando a importância da educação no contexto de conhecimento e prevenção de doenças. (RIBEIRO et al., 2018). Assim, ao se considerar a importância da disseminação de informações e sua associação com a vulnerabilidade social, é proposto o conceito de vulnerabilidade em informação, o qual ressalta os danos causados pelo excesso de exposição ou falta de acesso à informação (VITORINO, 2019). Nesse sentido, a Educação Popular em Saúde aparece como importante estratégia na redução das desigualdades sociais e na articulação dos princípios do SUS (PINHEIRO; MARIA; BITTAR, 2017), sobretudo na garantia da integralidade e da equidade em saúde.

Sob a perspectiva de intercâmbio de conhecimentos para auxílio no alcance da equidade em saúde, bem como na tentativa de proporcionar um acesso igualitário a ações de promoção, proteção e recuperação da saúde, docentes, técnicos, discentes do curso de Medicina da Universidade Federal de Jataí (UFJ) e profissionais da saúde colaboradores promoveram atividades de Educação Popular em Saúde. Tais atividades foram direcionadas para os indivíduos atendidos nos CRAS do município de Jataí-Goiás, assim como para outra Unidade Socioassistencial do município, o Centro de Convivência Projeto Abelha (CCPA), o que foi possível por meio do projeto de extensão "Informação é Saúde", em parceria com a Secretaria Municipal de Desenvolvimento Social e Cidadania de Jataí-GO. O objetivo foi garantir integralidade e equidade em saúde e da humanização do cuidado, sobretudo para o público em vulnerabilidade socioeconômica atendido neste projeto.

Dessa forma, este trabalho objetiva relatar a implantação e execução do projeto, de modo a contribuir para os conhecimentos acerca da extensão universitária no contexto da Educação Popular em Saúde.

\section{Metodologia}

\section{Implementação do projeto de Extensão Universitária em Unidades Socioassistenciais}

Estre trabalho não se configura como projeto de pesquisa e não necessita de registro pelo sistema CEP/CONEP, segundo a Resolução 510 de 2016, em seu Artigo $1^{\circ}$, que diz que atividade realizada com o intuito exclusivamente de educação, ensino ou treinamento sem finalidade de pesquisa científica, de alunos de graduação, de curso técnico ou de profissionais 
em especialização não serão registradas nem avaliadas pelo sistema CEP/CONEP(CONSELHO NACIONAL DE SAÚDE, 2016). O projeto foi cadastrado no sistema inte-grado de gestão de atividades acadêmicas da UFJ (PJ291-2018) com a uma equipe composta por 13 docentes da área da saúde - 4 médicos, 1 biomédico, 1 odontólogo, 2 psicólogos, 1 nutricionista, 1 farmacêutico, 2 biólogos e 1 médico veterinário; 2 biomédicos servidores da universidade, além de 3 profissionais da saúde externos à instituição - 1 odontólogo, 1 fisioterapeuta e 1 educador físico, além de 77 acadêmicos do curso de Medicina da UFJ do $4^{\circ}$ ao $11^{\circ}$ período.

No total, foram abordadas 20 temáticas ao longo das atividades, que foram distribuídas nos locais atendidos. Ainda, uma mesma temática foi contemplada em mais de um local, comforme a demanda do público-alvo. Para tanto, os participantes do projeto foram divididos em grupos de 5 a 10 alunos, coordenados por, pelo menos, um docente, e distribuídos de forma que todos tivessem o mesmo grau de participação nas ações, em relação à carga horária total do projeto.

Para o início das atividades oficiais, uma ação-piloto sobre os cânceres de mama e próstata foi realizada em uma das unidades do CRAS do município em novembro de 2017, sendo o público-alvo do primeiro ano de ações composto por idosos em situação de vulnerabilidade socioeconômica; e, após esse período, outras duas unidades do CRAS do município e o CCPA fizeram vínculo ao projeto, nas quais outras faixas etárias eram atendidas além do público idoso.

O planejamento do encontro foi realizado mediante reuniões técnico-científicas entre discentes e docentes. Foram levantados artigos científicos, notícias e publicações referentes à temática. Na atividade, optou-se pela realização de uma roda de conversa com conteúdo adaptado à linguagem popular regional para garantir a compreensão do tema por parte do público-alvo. Como feedback, ao final da atividade, foi estabelecido um debate sobre o assunto e os idosos se mostraram receptivos às informações sobre saúde a eles prestadas, apresentaram questionamentos e compartilharam experiências. Além disso, manifestaram a necessidade de esclarecimento sobre demais temas como hipertensão arterial, diabetes e outros tipos de câncer.

A partir deste piloto, foi possível perceber quais eram os tipos de abordagens mais apropriadas para esse público e o grau de entendimento quanto à linguagem empregada, bem como a receptividade para com a equipe da atividade, o que forneceu subsídios para o cadastramento e planejamento das demais ações do projeto.

As atividades foram desenvolvidas mensalmente, conforme as demandas da população atendida no âmbito da Secretaria Municipal de Desenvolvimento Social e Cidadania de JataíGO, as quais eram repassadas pelas assistentes sociais dos CRAS do município de Jataí-GO. Para cada tema selecionado, uma equipe de docentes, discentes e profissionais de saúde cadastrados no projeto, cujo conhecimento atendia a demanda, se reuniu para a elaboração de ideias, assim como para o preparo dos materiais necessários para as atividades idealizadas. É importante ressaltar que cada atividade foi planejada considerando o conteúdo a ser abordado, o públicoalvo e suas condições socioeconômicas e cognitivas. Vale salientar que, após um ano das atividades, o projeto se expandiu para atuação nas demais Unidades Socioassistenciais do município 
que não atendiam exclusivamente o público idoso, sendo necessárias adaptações das atividades de Educação Popular em Saúde para atender à faixa etária do novo público.

No que diz respeito às metodologias empregadas, várias foram usadas para viabilizar a adequada troca de informações. Para o preparo das atividades, foram elaboradas apresentações expositivas, dinâmicas práticas, como o treinamento para atividades físicas adaptáveis ao domicílio, situações clínicas para problematização, roteiros para apresentações teatrais e materiais audiovisuais. Nos encontros com o público-alvo, foram empregadas rodas de conversa, palestras expositivo-dialogadas, dinâmicas de perguntas e respostas, discussão sobre mitos e verdades, discussão de situações clínicas e interação por meio de artes cênicas, artes plásticas e uso do material audiovisual produzido.

As ações foram registradas por meio de fotografias e de relatório escrito realizados pelos membros da equipe executora do projeto. Nos relatórios, eram descritas as ações desenvolvidas, a percepção da equipe quanto à receptividade do público-alvo e a devolutiva do público ao final da atividade. A percepção do público foi relatada de forma subjetiva, não sendo registradas falas individuais dos participantes.

\section{Educação Popular em Saúde para idosos em vulnerabilidade socioeconômica}

As atividades de Educação Popular em Saúde com a população idosa foram desenvolvidas nos CRAS do município. Nessas ações, alunos do curso de medicina foram acompanhados por docentes e profissionais da saúde para a disseminação de informações, de forma acessível e inclusiva. As temáticas foram as mais diversificadas e incluíram: prevenção e manejo do diabetes mellitus; depressão no idoso; higienização de alimentos e prevenção de infecções parasitárias; exercício físico para o idoso; prevenção e manejo da hipertensão arterial sistêmica; osteoporose no idoso; prevenção do câncer de mama; prevenção do câncer de boca; cuidados com a saúde bucal no idoso; impactos da alimentação rica em sódio; queimaduras; prevenção e manejo da tuberculose; prevenção e manejo da dengue; qualidade de vida no envelhecimento e prevenção de quedas.

No grupo dos idosos, considerando o interesse do público e a importância da construção de um espaço para o relato de experiências, preferiu-se a adoção de dinâmicas como as discussões de mitos e verdades, rodas de conversa, discussão de situações clínicas e aplicação de práticas para o cotidiano, como a identificação de alimentos potencialmente agravantes de quadros de hipertensão arterial e diabetes mellitus e a prática de atividades físicas que poderiam ser adaptadas para a realização no domicílio.

\section{Educação Popular em Saúde para crianças e adolescentes em vulnerabilidade socioeconômica}

As ações de Educação Popular em Saúde com o público infanto-juvenil foram desenvolvidas no CCPA, local que atende cerca de 300 crianças e adolescentes, divididos em dois períodos. A entidade promove atividades diversificadas voltadas para o esporte, lazer, cultura e desenvolvi- 
mento social, de modo a contribuir para a redução das desigualdades socio-econômicas e culturais vivenciadas pelo público atendido. Para a realização das atividades no lugar, foram formados três grupos para atividades direcionadas a idades distintas: de 5 a 9 anos, de 9 a 12 anos e de 12 a 17 anos, conforme recomendações da coordenação local.

As temáticas das atividades desenvolvidas com este grupo incluíram: a higienização de mãos, a prevenção de doenças infectocontagiosas e a prevenção do uso de drogas pelo público infanto-juvenil. Para tanto, diversas metodologias foram utilizadas, incluindo artes cênicas (com ou sem o uso de fantoches), artes plásticas, apresentação de vídeos, cartazes e desenhos, jogos de perguntas e respostas, prática com as crianças de lavagem adequada das mãos, rodas de conversa e jogos de avaliação dos conhecimentos em saúde envolvendo disputa entre equipes formadas pelas crianças e adolescentes que frequentavam a CCPA, com premiação simbólica.

\section{Resultados}

O trabalho foi desenvolvido em 3 CRAS e no CCPA. No primeiro CRAS, no qual as ações do projeto tiveram início, foram promovidos 21 encontros, sendo 1 encontro por mês, exceto nos meses de janeiro, fevereiro e julho, correspondentes ao recesso acadêmico. Em cada encontro, uma média de 25 idosos participaram das ações. Nos outros dois CRAS, as ações foram desenvolvidas em uma frequência menor, totalizando 10 ações, distribuídas ao longo do período de atividade do projeto, conforme demanda do local. Nestas últimas ações, participaram cerca de 20 adultos e 15 idosos. Por fim, foram desenvolvidas duas ações no CCPA, distribuídas em três turmas, conforme faixa etária, e em dois turnos distintos, totalizando, em média, 300 crianças em cada ação. Todas as atividades tiveram duração média de 2 horas.

As atividades interativas e lúdicas permitiram que os integrantes do projeto pudessem exercer a escuta e, assim, viabilizar a horizontalização do conhecimento e a troca entre a equipe executora e o público-alvo. Ao permitir que o público-alvo das atividades expusessem seus conhecimentos e crenças acerca do cuidado com a saúde, os integrantes do projeto puderam refletir sobre os diferentes contextos e como isso interfere na educação em saúde. Os encontros permitiram a popularização do conhecimento científico, socialização, qualificação profissional e, especialmente, humanização do cuidado, tendo como base o emprego de linguagem acessível.

A popularização do conhecimento científico ocorreu, sobretudo, por meio do diálogo estabelecido entre os membros do projeto e o público-alvo. O resgate dos conhecimentos prévios por parte da comunidade atendida foi a base para o início do diálogo. Na população idosa, durante os encontros realizados, foi frequente o relato de experiências pessoais que se relacionavam com os temas apresentados, sobretudo no que se refere a temáticas que faziam parte de seu cotidiano, como é o caso das doenças crônicas. 
As atividades desenvolvidas com os idosos dos CRAS reforçaram a importância da manutenção do cuidado com esse público. Conforme exposto na Figura 1, a seguir, as metodologias empregadas priorizaram a interação dos alunos com os participantes da comunidade, dando oportunidade para que eles desenvolvessem vínculos com a equipe executora do projeto e compartilhem saberes, vivências e práticas populares.

Figura 1 - Atividades de Educação Popular em Saúde com grupo de idosos. A) Aferição de pressão arterial em atividade sobre hipertensão arterial sistêmica. B) Atividade de mitos e verdades sobre o câncer de próstata. C) Prática de atividades físicas com idosos. D) Roda de conversa sobre o setembro amarelo e a saúde mental do idoso.

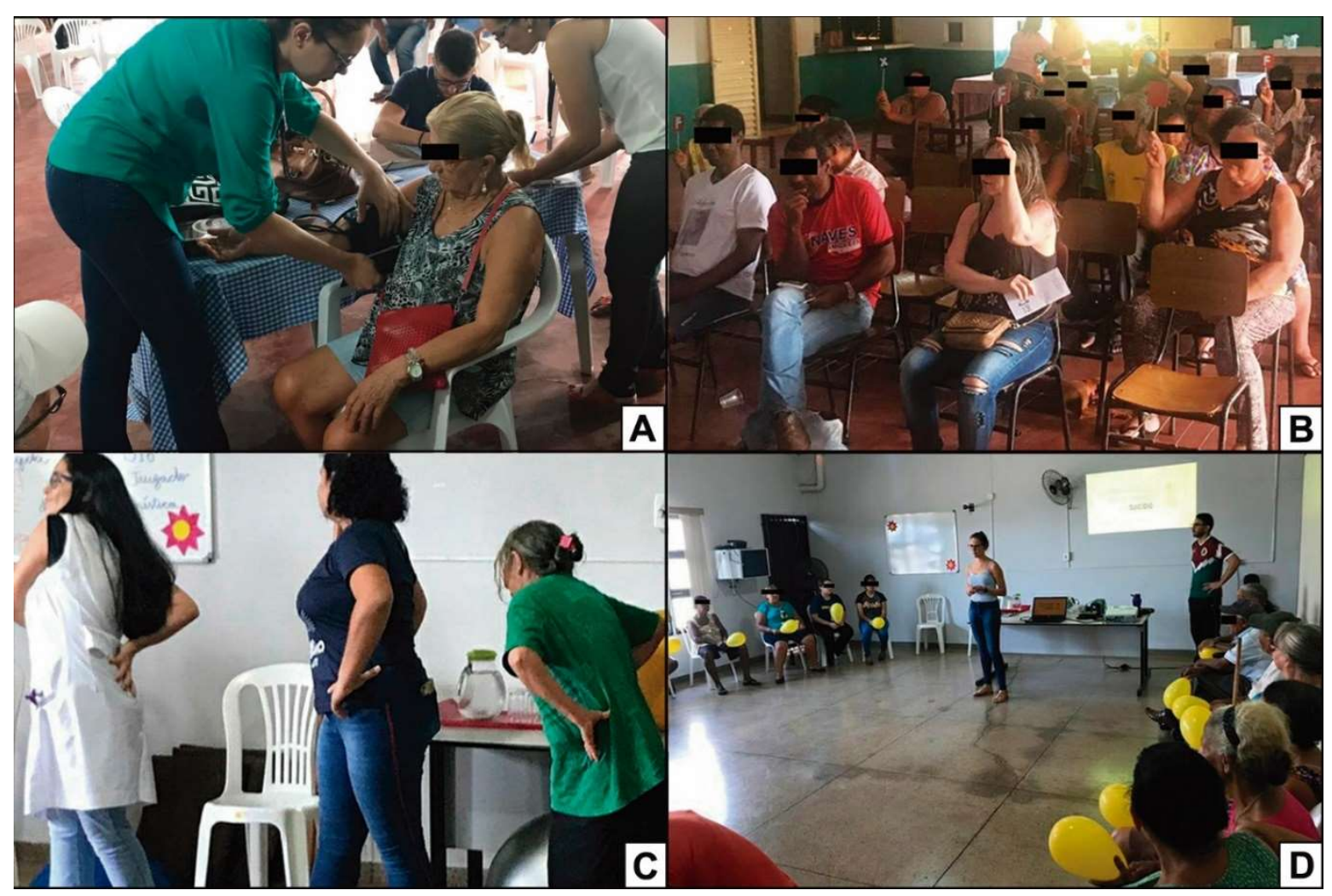

Fonte: Autores.

Nas dinâmicas com o público infanto-juvenil, o emprego de metodologias viabilizou a interação entre a equipe executora do projeto e o público-alvo. Tomando como foco a temática central do momento da ação, a programação das atividades levou em consideração a idade do grupo participante, a capacidade cognitiva e a vulnerabilidade socioeconômica. Dessa forma, optou-se por uma abordagem prática, interativa e lúdica dos conhecimentos técnico-científicos em saúde e da Educação Popular em Saúde, conforme exposto na Figura 2. 
Figura 2 - Atividades de Educação Popular em Saúde com crianças e adolescentes. A) Teatro de fantoches sobre higienização das mãos com crianças entre 5 e 9 anos. B) Teatro sobre prevenção do uso de drogas com crianças entre 5 e 9 anos. C) Prática de higienização de mãos com crianças entre 9 e 12 anos. D) Dinâmica de perguntas e respostas sobre prevenção do uso de drogas com adolescentes entre 12 e 19 anos.

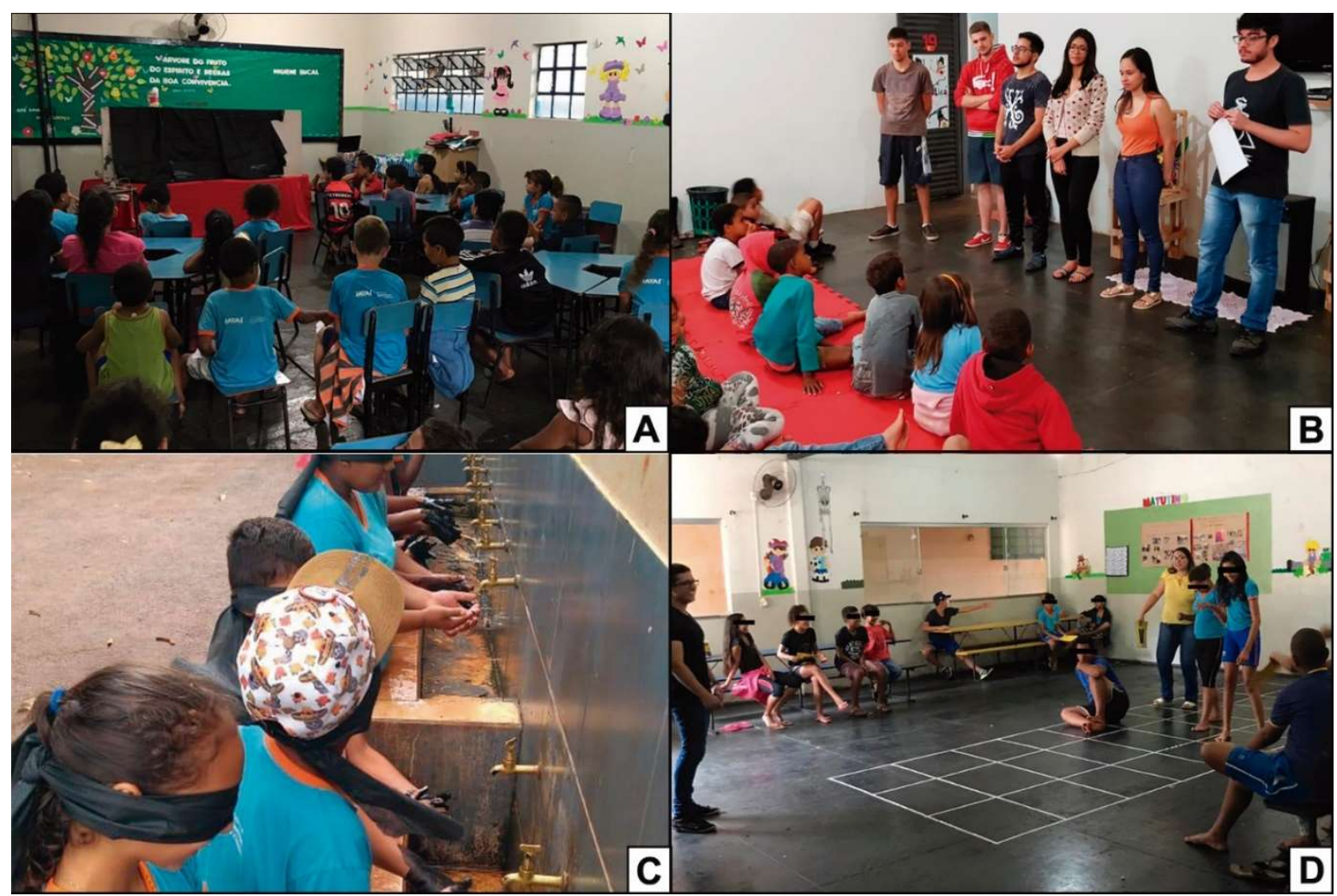

Fonte: Autores.

\section{Discussão}

O contato com a comunidade em situação de vulnerabilidade socioeconômica reforçou o papel da Educação Popular em Saúde na popularização do conhecimento científico. A literatura aponta, ainda, que tais práticas educativas são cruciais na promoção da saúde, constituindo o eixo central das atividades extensionistas nos cursos de medicina. Tais atividades são desenvolvidas de modo a promover a integração entre o sistema de graduação, as instituições em saúde e a comunidade, visando o desenvolvimento do senso de responsabilidade social, científica, tecnológica, econômica, política, promocional e cultural, o que reforça a formação de vínculo entre os estudantes e a comunidade (VELIZ GUTIÉRREZ et al., 2011).

Os espaços oferecidos pelos CRAS permitiram a criação de um grupo de convivência, interação e conhecimento, formado pela população atendida pelas unidades socioassistenciais e pelos membros da equipe executora do projeto. Desse modo, é possível afirmar que, além 
de substituir momentos de solidão, sentimento comum a muitos idosos, esses encontros favoreceram não só uma melhora da autoestima e da autonomia, quanto promoveram maior busca por melhores condições de saúde, uma vez que os idosos desejam continuar aprendendo e experimentando novas atividades.

Isto vai ao encontro da pesquisa desenvolvida por Gomes e colaboradores (2014), a qual envolveu 30 idosos participantes de um projeto de extensão que trabalhava com a temática de Envelhecimento Saudável. No projeto, eram desenvolvidas atividades diversas voltadas para a satisfação e desejo do idoso, atendimento às necessidades físicas e orientação para o manejo e domínio do ambiente físico e social. Nesse estudo, os idosos foram entrevistados e a análise de suas respostas demonstrou que a concepção religiosa pode ser determinante e condicionante no bem-estar e na saúde dos idosos. Além disso, notou-se que os grupos de convivência lhes proporcionaram melhora no processo cognitivo, no lazer e na socialização, de modo que a extensão universitária levou à redução da frequência e a intensidade de afetos negativos oriundos do processo de envelhecimento (GOMES et al., 2014).

No entanto, para que a Educação Popular em Saúde supra as demandas desse público em questão, é necessário que se trabalhe com metodologias que englobem a complexidade do processo de envelhecimento e relacionem os fatores que sejam condizentes com as necessidades dos indivíduos (MALLMANN et al., 2015). Nessa conjuntura, a capacidade funcional, o grau de independência e a autonomia dos idosos caracteriza sua vida como ativa ou não. Por isso, eles almejam o conhecimento, a informação, a construção de laços sociais e o respeito com as suas singularidades. Desse modo, as políticas públicas, os programas e os projetos destinados ao cuidado com a saúde dessa parcela da população devem aprimorar, proporcionar ou recuperar esses elementos, como objetivado neste trabalho (DE SOUZA; SILVA; DE BARROS, 2019; GOMES et al., 2014).

No que se refere à educação em saúde com crianças e adolescentes, a discussão entre os integrantes do projeto, o público-alvo e as assistentes sociais responsáveis pelas unidades atendidas, evidenciou-se a importância do emprego de atividades atrativas e de fácil assimilação.

Conforme observado por Costa e colaboradores (2015), as rodas de conversas, com a abordagem dos temas de maneira lúdica com os escolares, mostraram-se como um meio que proporcionou maiores chances de aprendizado e de participação. Os autores, da mesma forma que no presente projeto, usaram o teatro de fantoches com pré-escolares e, em ambos os casos, esse método foi visto como uma abordagem eficaz para a educação em saúde com o público em questão (COSTA et al., 2015). Tais achados vão ao encontro do fato de que a arte permite a interação, a identificação e o cuidado pautado na ciência, associado à expressão da alegria, do entretenimento e da integralidade do ser humano (SOUSA; VICTOR, 2007).

Com base nisso, e ao considerar que o lúdico é uma linguagem compreensível às crianças e aos adolescentes, o uso das artes teatrais é uma ferramenta pedagógica coerente para a promoção à saúde na infância, além de ser uma experiência considerada bem sucedida (SILVA et al., 2017). 
Nesse sentido, os membros do projeto optaram pela realização de dinâmicas lúdicas e interativas, como a apresentação teatral, na tentativa de envolver o público na atividade.

Acrescenta-se, ainda, que jogos de perguntas e respostas, rodas de conversa com apresentação expositivo-dialogada e jogos de avaliação dos conhecimentos em saúde, realizados no público infanto-juvenil atendido neste projeto, provocam debate entre os membros, auxiliam no processo de respeito à fala do outro e ao espaço para escuta, valorizam o conhecimento prévio dos participantes e possibilitam o empoderamento do grupo. Assim, Oliveira e colaboradores demonstraram também a relevância de ações de Educação Popular em Saúde na assistência a crianças e adolescentes, de modo a merecerem ser priorizadas e planejadas para adoção de práticas e políticas de saúde adequadas por equipe multiprofissional da Estratégia Saúde da Família (OLIVEIRA et al., 2009).

Frente ao exposto, acredita-se que este projeto oferece, também, a melhoria na formação de futuros profissionais de saúde ao viabilizar a prática de estratégias para o enfrentamento de vulnerabilidades sociais através da popularização do conhecimento científico.

\section{Considerações finais}

A participação da comunidade nos encontros realizados nos CRAS e CCPA, além de permitir a participação em saúde, proporcionou o fortalecimento da convivência comunitária de idosos, crianças, jovens e adultos com a comunidade acadêmica - docentes, discentes, técnicos e demais profissionais envolvidos. A realização de ações de extensão na comunidade, atendendo aos seus interesses e demandas, é de extrema relevância, pois permite a aproximação e a troca de experiências entre os acadêmicos e a comunidade, estimulando a formação crítica e humanizada.

Além disso, as atividades reforçam a importância de ações de Educação Popular em Saúde para a garantia da integralidade e da equidade em saúde, sobretudo no público em vulnerabilidade socioeconômica. Considerando o papel social da Universidade no contexto da popularização do conhecimento científico e na oferta de serviços de extensão universitária que atendam às demandas locais, a interação universidade-comunidade aqui apresentada é vista como uma importante estratégia para a redução das iniquidades sociais, políticas e em saúde.

Para a adoção de ações assertivas no contexto da extensão universitária, é essencial que as equipes conheçam a realidade local e as demandas da população. Nesse sentido, este projeto reforça a importância da articulação entre os membros da comunidade universitária e as entidades representativas da comunidade, como é o caso da interação entre os membros do projeto e as assistentes sociais das unidades atendidas.

Acredita-se, ainda, que as ações de extensão com enfoque na Educação Popular em Saúde, como a relatada neste trabalho, possam contribuir de forma significativa na formação dos acadêmicos da área da saúde ao viabilizar um espaço de promoção da interação inter- 
disciplinar e multiprofissional, bem como de aplicação de habilidades de comunicação essenciais para a garantia de um atendimento em saúde equalitário.

Por fim, acrescenta-se que o trabalho apresentou limitações para a avaliação objetiva das ações pelas pessoas que frequentavam os CRAS e a CCPA. As ações foram avaliadas de forma qualitativa e agrupada, não sendo inseridos relatos individuais e/ou avaliações quantitativas da qualidade e importância do trabalho desenvolvido.

\section{Agradecimentos}

Aos funcionários da Secretaria Municipal de Desenvolvimento Social e Cidadania de Jataí-GO, dos Centros de Referência de Assistência Social Vila Sofia, Mauro Bento e Jardim da Liberdade e do Centro de Convivência Projeto Abelha. Aos alunos, docentes, servidores e convidados que contribuíram para a execução das atividades do projeto. Ao apoio da PróReitoria de Extensão e Cultura (PROEC) da Universidade Federal de Jataí.

\section{Referências}

BRASIL. Lei no 8.742 de 7 de dezembro de 1993. Dispõe sobre a organização da Assistência Social e dá outras providências. Diário Oficial da União, 8 dez. 1993. Disponível em: https://www.planalto.gov.br/ccivil_03/leis/18742.htm. Acesso em: 16 set. 2020.

BRASIL. Portaria no 2.761, de 19 de novembro de 2013. Institui a Política Nacional de Educação Popular em Saúde no Âmbito do Sistema Único de Saúde (PNEPSSUS). Brasília: Ministério da Saúde, 2013. Disponível em: https://www.jusbrasil.com.br/diarios/61902081/dousecao-1-20-11-2013-pg-62. Acesso em: 16 set. 2020.

CONSELHO NACIONAL DE SAÚDE. Resolução $\mathbf{n}^{\mathbf{0}}$ 510, de 7 de abril de 2016. Dispõe sobre a pesquisa em Ciências Humanas e Sociais. Brasília, 2016. Disponível em: http://bvsms.saude.gov.br/bvs/saudelegis/cns/2016/res0510_07_04_2016.html. Acesso em: 24 maio 2021

COSTA, D. V. DA S. et al. Extensão universitária na promoção da saúde infantil: Analisando estratégias educativas. Revista Ciência em Extensão, v. 11, n. 1, p. 25-31, 2015.

DE SOUZA, E. M. DE; SILVA, D. P. P.; DE BARROS, A. S. Educação popular, promoção da saúde e envelhecimento ativo: Uma revisão bibliográfica integrativa. Ciência \& Saúde Coletiva, v. 26, n. 4, p. 1355-1368, 2021. 
DO AMARAL, M. C. S.; PONTES, A. G. V.; E SILVA, J. D. V. O ensino de Educado Popular em Saúde para o SUS: Experiencia de articulado entre graduandos de enfermagem e Agentes Comunitários de Saúde. Interface: Communication, Health, Education, v. 18, n. 2, p. 1547-1558, 2014.

FIGUEIREDO, M.; NETO, J.; LEITE, M. Modelos aplicados às atividades de educação em saúde. Revista Brasileira de Enfermagem, v. 63, n. 1, p. 117-121, 2010.

GOMES, H. et al. Extensão Universitária: A arte de cuidar de idosos. Revista de Ciências da Saúde Nova Esperança, v. 12, n. 1, p. 24-36, 2014.

MALLMANN, D. G. et al. Educação em saúde como principal alternativa para promover a saúde do idoso. Ciência \& Saúde Coletiva, v. 20, p. 1763-1772, 2015.

\section{MINISTÉRIO DO DESENVOLVIMENTO SOCIAL E COMBATE A FOME. Política} Nacional de Assistência Social, 2004.

OLIVEIRA, C. B. et al. As ações de educação em saúde para crianças e adolescentes nas unidades básicas da região de Maruípe no município de Vitória. Ciência \& Saúde Coletiva, v. 14, n. 2, p. 635-644, 2009.

PINHEIRO, B. C.; MARIA, C.; BITTAR, L. Práticas de educação popular em saúde na atenção primária : uma revisão integrativa Practices of popular education in health in primarycare: an integrative review. Revista do Departamento de Educação Física e Saúde e do Mestrado em Promoção da Saúde da Universidade de Santa Cruz do Sul / Unisc, v. 18, n. 1, p. 77-82, 2017.

RIBEIRO, K. G. et al. Education and health in a region under social vulnerability situation: Breakthroughs and challenges for public policies. Interface: Communication, Health, Education, v. 22, n. 1, p. 1387-1398, 2018.

SANTOS, Á. Educação em saúde: reflexão e aplicabilidade em atenção primária á saúde.

Online Brazilian Journal of Nursing, v. 5, n. 2, p. 258-268, 2006.

SILVA, C. B. DA et al. Atividades de educação em saúde junto ao ensino infantil: relato de experiência. Revista de Enfermagem UFPE on line, v. 11, n. 12, p. 5455, 2017.

SOUSA, R. A. DE; VICTOR, J. F. Grupo de teatro de fantoches Saúde com Arte: proposta de enfermagem para educação em saúde. Rev. RENE, v.8, n. 2, p. 79-84, 2007. 
TEIXEIRA, S. M. Trabalho Interdisciplinar nos CRAS: um novo enfoque e trato à pobreza? Textos \& Contextos, v. 9, n. 2, p. 286-297, 2010.

VASCONCELOS, E. M. Redefinindo as práticas de Saúde a partir de experiências de Educação Popular nos serviços de saúde. Interface - Comunicação, Saúde, Educação, v. 5, n. 8, p. 121-126, 2001.

VELIZ GUTIÉRREZ, J. A. et al. La Extensión Universitaria y la Promoción de Salud en la Atención Primaria. Revista de Ciencias Médicas de Pinar del Río, v. 15, p. 218-230, 2011.

VERDI, M.; BUCHELE, F.; TOGNOLI., H. Educação em saúde. Florianópolis: UFSC, 2010.

VITORINO, E. V. A competência em informação e a vulnerabilidade: construindo sentidos à temática da "vulnerabilidade em informação". Pesquisa Brasileira em Ciência da Informação e Biblioteconomia, v. 14, n. 1, p. 71-85, 2019. 